International Journal of Biology, Pharmacy and Allied Seiences (IJBPAS) 'A Bridge Betuen Caboratory and Qnendo'

WWW.ijbpas.com

\title{
PREVALENCE OF ORAL ULCERS AMONG THE POPULATION OF CHENNAI: AN INSTITUTIONAL STUDY
}

\section{SABARATHINAM $\mathrm{J}^{1}$, CHAUDHARY $\mathrm{M}^{2}$, AND MADHULAXMI $\mathrm{M}^{3}$}

1: Saveetha Dental College \& Hospitals, Saveetha Institute Of Medical \& Technical Sciences (SIMATS), Saveetha University, Chennai 600077, India

2: Senior Lecturer, Department of Oral Medicine and Radiology, Saveetha Dental College \& Hospitals, Saveetha Institute Of Medical \& Technical Sciences (SIMATS), Saveetha University, Chennai 600077, India

3: Professor, Department of Oral \& Maxillofacial Surgery, Saveetha Dental College \& Hospitals, Saveetha Institute Of Medical \& Technical Sciences (SIMATS), Saveetha University, Chennai 600077, India *Corresponding Author: E Mail: Dr. Manjari Chaudhary: manjaric.sdc@saveetha.com

Received $20^{\text {th }}$ March 2021; Revised 26 ${ }^{\text {th }}$ April. 2021; Accepted $24^{\text {th }}$ May 2021; Available online $1^{\text {st }}$ Aug. 2021

\section{https://doi.org/10.31032/IJBPAS/2021/10.8.1090}

\section{ABSTRACT}

The study was aimed to assess the prevalence of oral ulceration and its association with gender among different types of ulcers among the patients reporting to a private institution in Chennai. The Study was conducted among 44000 patients attending the outpatient department of Saveetha Dental College, Chennai, during a time period of 6 months from June 2019- December 2019. The data was procured from electronic device and patient records were assessed and interpreted for the number of patients diagnosed with oral ulcers. The obtained data was tabulated using MS-Excel and analysed and interpreted with IBM SPSS software. The prevalence of oral ulcers among the patients reporting to Saveetha Dental College was $0.59 \%$ among which $60 \%$ were traumatic ulcers while $22 \%$ was aphthous ulcer. Herpetic ulcers were recorded the least with 18\%. Male predilection was observed among traumatic and aphthous ulcers. Within the limitations of our current study, It is concluded that the prevalence of oral ulcers among Chennai population is $0.59 \%$, among which traumatic ulcers were the most accounted for more than $50 \%$.

Keywords: Aphthous ulcer, Herpes, Oral ulcers, Traumatic ulcers 


\section{INTRODUCTION}

Oral ulcerations is one of the most frequent reasons to take an oral medicine consultation [1-3] when compared to other lesions such as carcinoma and potentially malignant disorders [4-7]. It is generally defined as discontinuity of the oral epithelium of mucosa which damages both epithelium and lamina propria $[\mathbf{8}, 9]$. The epithelium and lamina propria is completely lost, unlike mucosal erosions which involve only loss of superficial areas of layers of oral epithelium. The most common site of involvement is buccal mucosa, cheeks, floor of the mouth and lips [10].

Clinically patients present with painful oral wounds that affect any part of the oral mucosa especially the lip, tongue and buccal mucosa [10]. These wounds are termed "Aphthae", a term of ancient origin which refers to oral mucosal surface ulcerations [10, 11].

The review of literature has well documented the etiology of oral ulceration $[8, \mathbf{1 1 - 1 3}]$. The presence of sharp edges of teeth, presence of mechanical appliances (fixed or removable dentures), orthodontic appliances, radiation and chemical injuries caused by medication are the utmost leading causative factors of traumatic ulcer [11, 14-17]. Removal of etiology of trauma is essential for management, while pain control and prevention supra-infections are essential for symptomatic relief [18].

Infectious ulcer originates due to presence of microorganism which is pathogenic in nature which could be bacteria (syphilitic ulcer, tuberculous ulcer), Virus (Herpes simplex), Fungi (Histoplasmosis) [11, 19] while the most common ulcerations are immune dysfunction ulcerations (aphthous ulcers) and stress induced ulcers [20, 21].

The etiological factors considered such as stress and psychological trauma are considered as notable factors which cause oral aphthous ulcers [20].

Pain and discomfort caused by the ulcers have been investigated to be associated with reduced quality of life. It is associated with difficulties in mastication and taste disturbances [20, 22, 23].

Even though oral ulceration is the most common clinical presentation in daily dental practice, information on the local experience and prevalence pattern of the condition among the people of chennai is inadequate. Our current study was aimed at assessing the prevalence of oral ulcerations among the patients reporting to a tertiary oral health care center with advanced diagnostic aids [24] (Saveetha Dental College and Hospitals). 


\section{MATERIALS AND METHODS}

This study was performed among the patients attending the outpatient department, of a private institution in Chennai, India during a time period of 6 months from June 2019 December 2019. The sample size of the current study was 44000 . The patient records were assessed and interpreted for the number of patients diagnosed with oral ulcers. Incomplete data without diagnostic notes and photographs were excluded from the study. Institutional ethical committee clearance was obtained for data retrieval and usage as needed for the study (SDC/SIHEC/2020/DIASDATA/0619-0320)

The verification of details was done in presence of two reviewers to minimize the observer's bias. The verification process was done with the help of photographs and diagnostic notes. The data obtained was tabulated in MS-Excel under the parameters such as age, gender and type of ulceration and ulcer's presence. The data was interpreted in IBM SPSS software (version 20) and the results were interpreted. Chi square test was performed.

\section{RESULTS AND DISCUSSION:}

The prevalence of oral ulceration in patients reporting to an institutional setup in Chennai was $0.59 \%$ with a male predilection $(61.6 \%)$ and less prevalent in females $(28.4 \%)$ (Figure 1).

The most commonly occuring ulcer was traumatic ulcer (45\%) followed by aphthous ulcer $(29 \%)$ and herpetic ulcers (26\%) (Figure 2).

The prevalence of traumatic ulcer was $0.27 \%$ with a male predilection (62.5\%) and females having lesser frequency (37.5\%). Patients between the age group 20-50 years had more frequency of occurrence of traumatic ulcers (Figure 3).

The prevalence of aphthous ulcer was $0.16 \%$ with a male predilection of $67.53 \%$ and females having lesser frequency of $35.47 \%$. Patients of age below 20 years had more frequency of occurrence of aphthous ulcers (Figure 4).

The prevalence of herpetic ulcer was $0.15 \%$ with no gender predilection. Patients between the age group 20-50 years had more frequency of occurrence of herpetic ulcers (Figure 5).

There was statistically significances between age groups and types of ulcers present in accordance to Pearson's Chi square test (p0.010) (Figure 6).

Oral ulcerations is one of the most common reasons for oral medicine consultation and has proven to reduce the quality of life due to the pain and discomfort during mastication 
$[22,25]$. It is frequently associated with taste changes. The prevalence of oral ulcerations among the patients reporting to saveetha dental college was observed to be $0.59 \%$. While the United States reported $4 \%$ prevalence [26], the Netherlands reported $2.5 \%$ prevalence [27] , turkey reported $6.6 \%$ prevalence [28], 12\% in north India [28, 29], and $20 \%$ prevalence among nigeria [30]. The results of our current study shows reduced or lesser prevalence than previous literature studies which implicates that patients are not reporting to dental clinics or hospitals for diagnosis and treatment of oral ulcerated lesions. This could be due to decreased awareness about ulcers or increased self medication for oral ulcers.

The prevalence of aphthous ulcers was $0.16 \%$ with a male predilection $(67 \%)$, while the turkish population reported $2.3 \%$ prevalence [28] of aphthous ulcer with a female predilection of $84 \%$ among the study population of 500 samples reported by Ali et al. This study contradicts the results of our current study where there is an increased prevalence. The study conducted on teenagers revealed that $18 \%$ prevalence of aphthous ulcers due to increase in stress and hormonal changes [31]. $0.5 \%$ was obtained in malaysia by rosnah binti et al [32] which was in ordinance with our study present. While $0.1 \%$ prevalence reported by yojali et al [33] was also equatable to our current study.

The prevalence of traumatic ulcers was $0.27 \%$ while in healthy teenagers was $14.3 \%$ [31], where the possible reason includes sports injuries and assaults being very common. Whereas the prevalence of $0.92 \%$ [28, 31] was observed among the turkish population which is in accordance with the current study. Nigerian population also showed $1.6 \%$ prevalence of traumatic ulcer $[28,30,31]$ which contradicts our current study in relation to higher prevalence. Most of the studies reported female predilection while our study reported male predilection.

The prevalence of herpetic ulcers is $0.15 \%$ in our current study, while turkish population observed $2 \%$ prevalence with a female predilection [28]. While Italy showed that teenagers have greater prevalence of herpetic lesions with a male predilection [31]. The results of our current study contradicts the results of the previous studies. This could be due to hormonal changes, gender and stress distribution among teenagers.

The limitations of our current study includes geographically isolated population, short term study, operator bias and availability of limited samples while the future scope of the study is to increase the time duration of the study and put forth standard protocols for diagnosis and treatment of ulcers. 


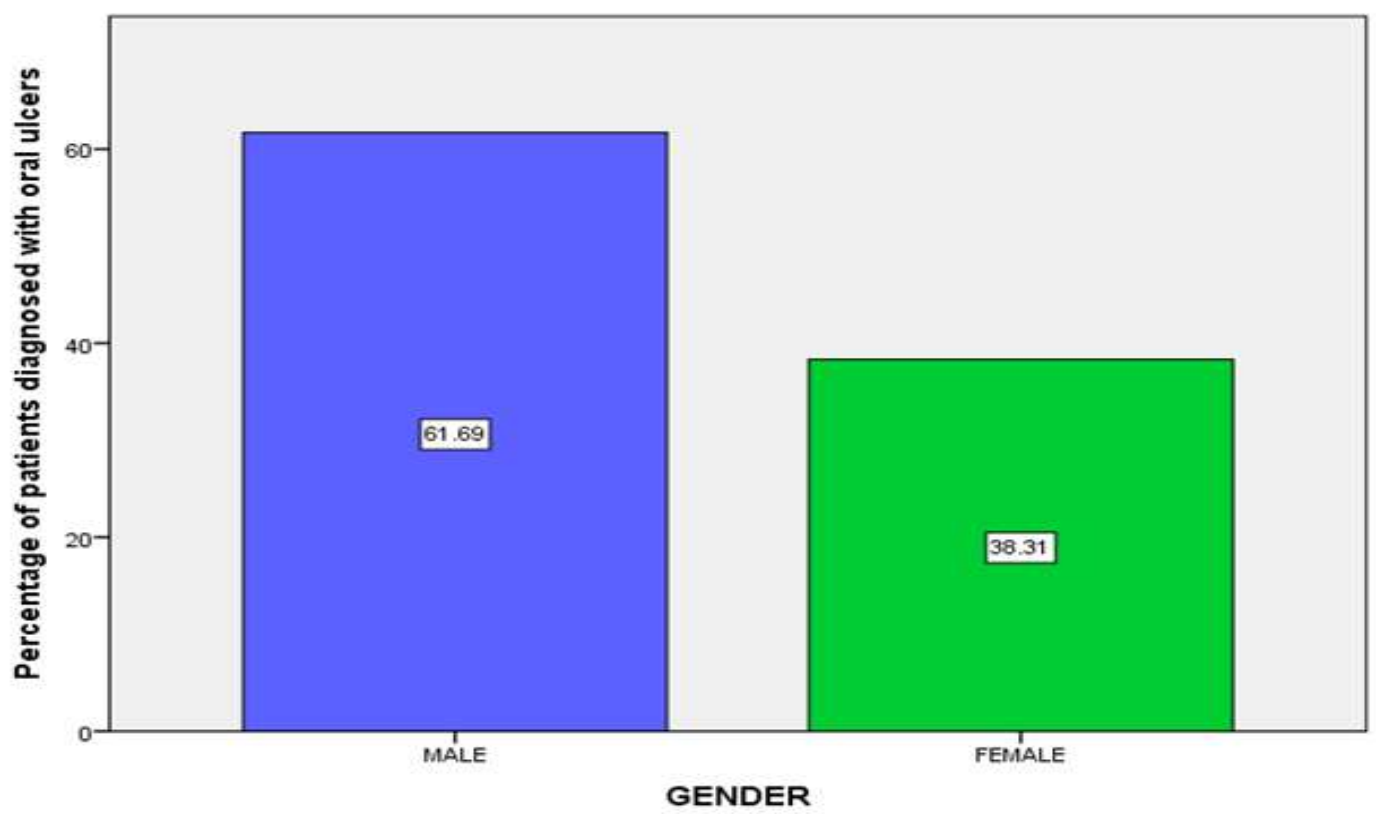

Figure 1: Bar graph depicts the percentage of males and females diagnosed with oral ulcers ; where $\mathrm{Y}$ axis shows the percentage of patients diagnosed with ulcers and $X$ axis shows the gender of patients.. Males (Blue) experienced increased frequency of ulcers in comparison to females (Green).

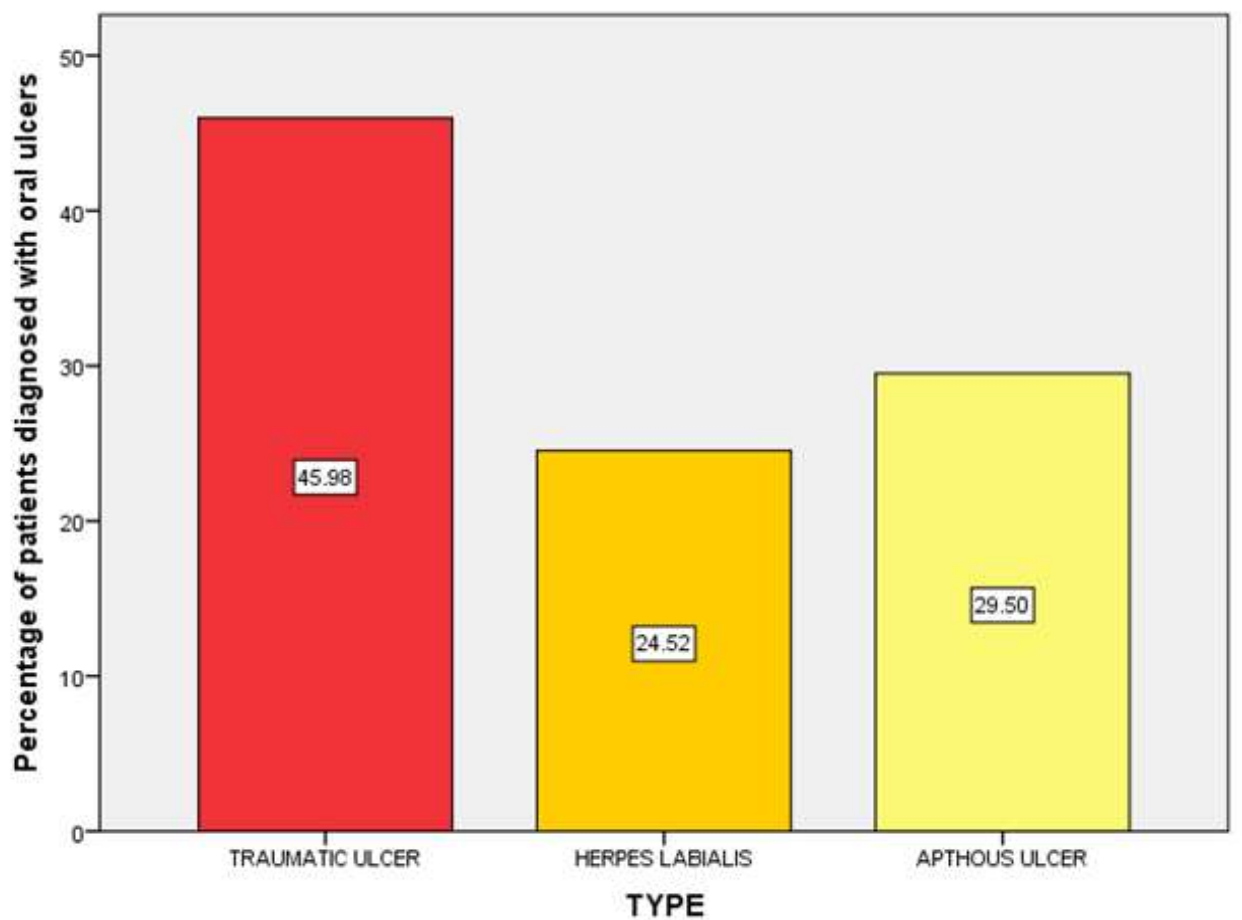

Figure 2: Bar graph depicts the percentage of patients diagnosed with various types of ulcers ; where $Y$ axis shows the percentage of patients diagnosed with ulcers and $X$ axis shows the various types of ulcers. Traumatic ulcers (Red) were the most frequently diagnosed ulcer among the study population in comparison to herpetic ulcers (Orange) and aphthous ulcers (Yellow). 


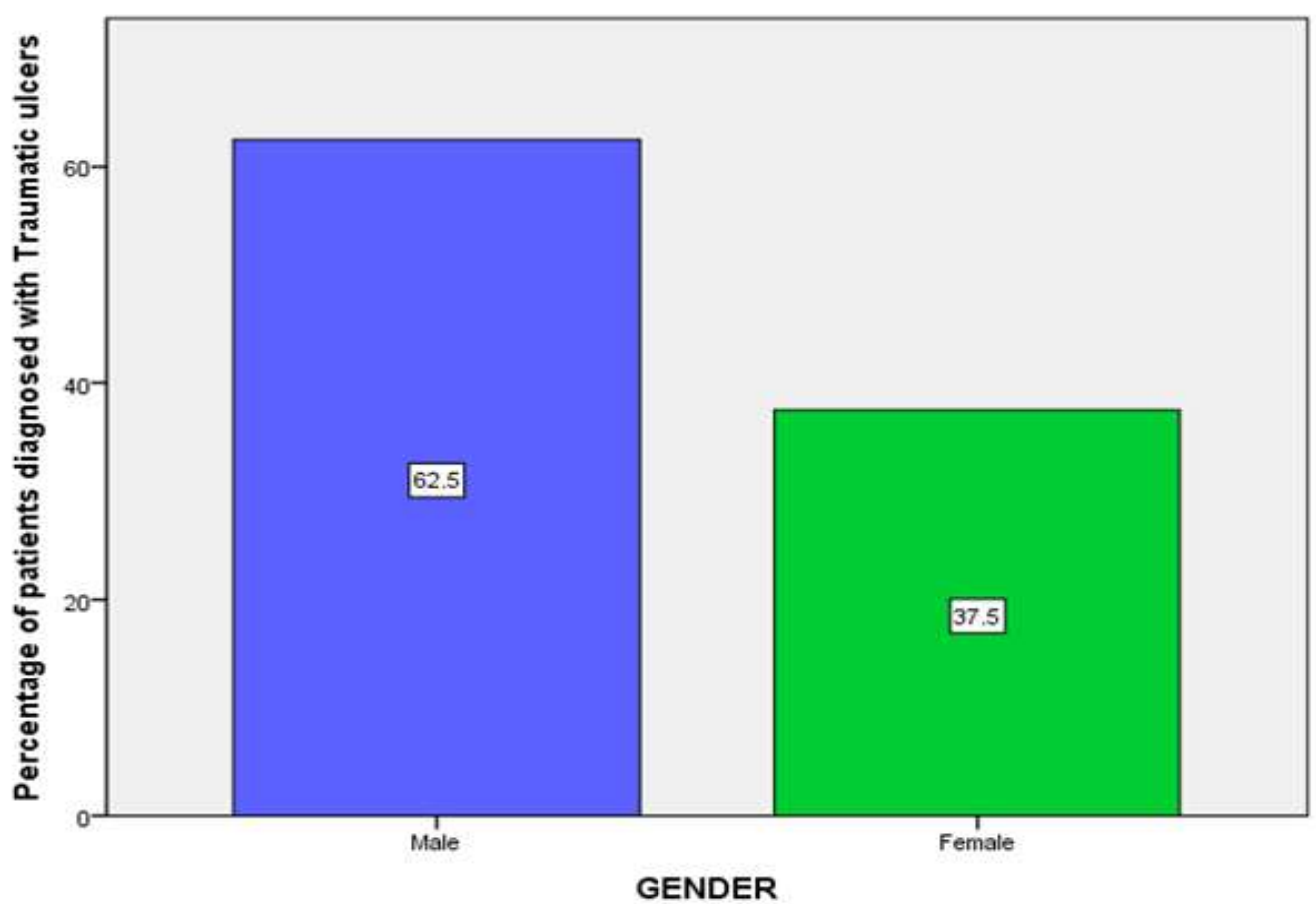

Figure 3: Bar graph depicts the percentage of males and females diagnosed with traumatic ulcers ; where $\mathrm{Y}$ axis shows the percentage of patients diagnosed with traumatic ulcers and $X$ axis shows the gender of patients. Males (Blue) experienced increased frequency of traumatic ulcers in comparison to females (Green).

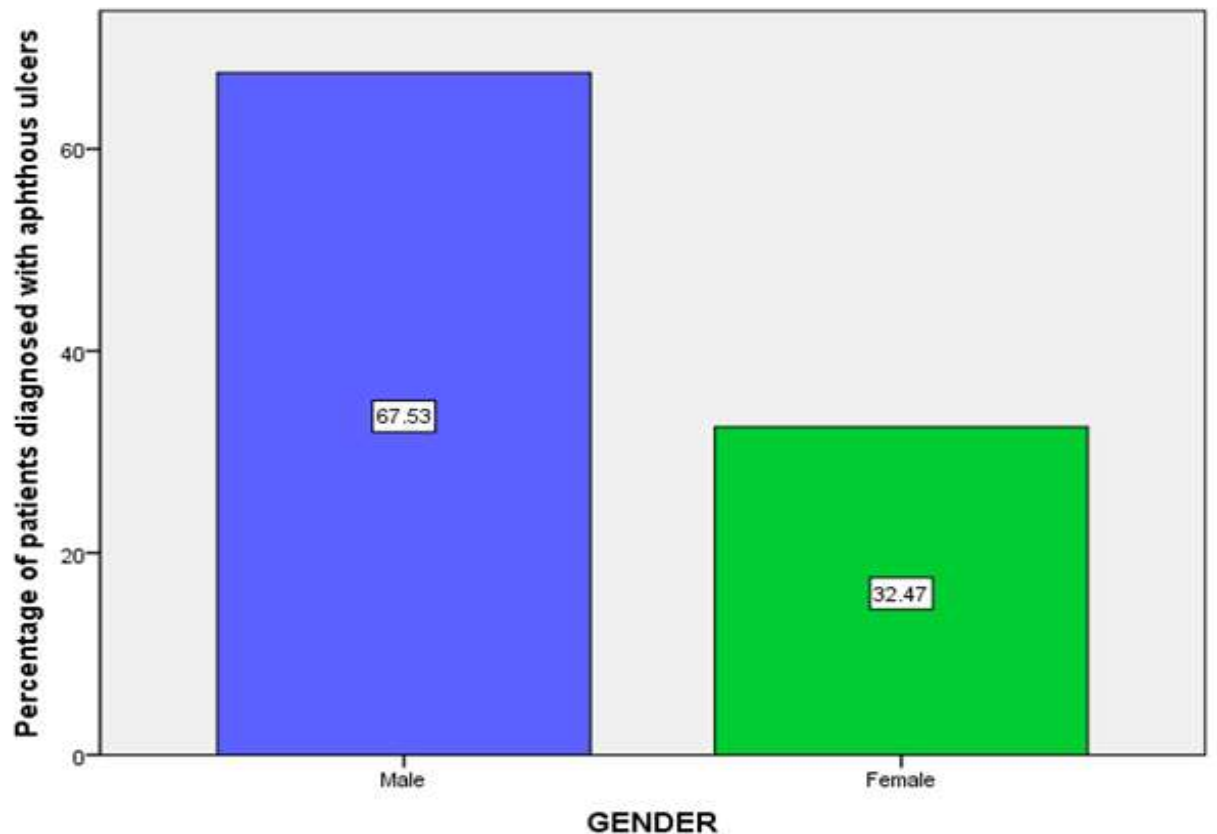

Figure 4: Bar graph depicts the percentage of males and females diagnosed with aphthous ulcers; where $Y$ axis shows the percentage of patients diagnosed with aphthous ulcers and $X$ axis shows the gender of patients. Males (Blue) experienced increased frequency of aphthous ulcers in comparison to females (Green). 


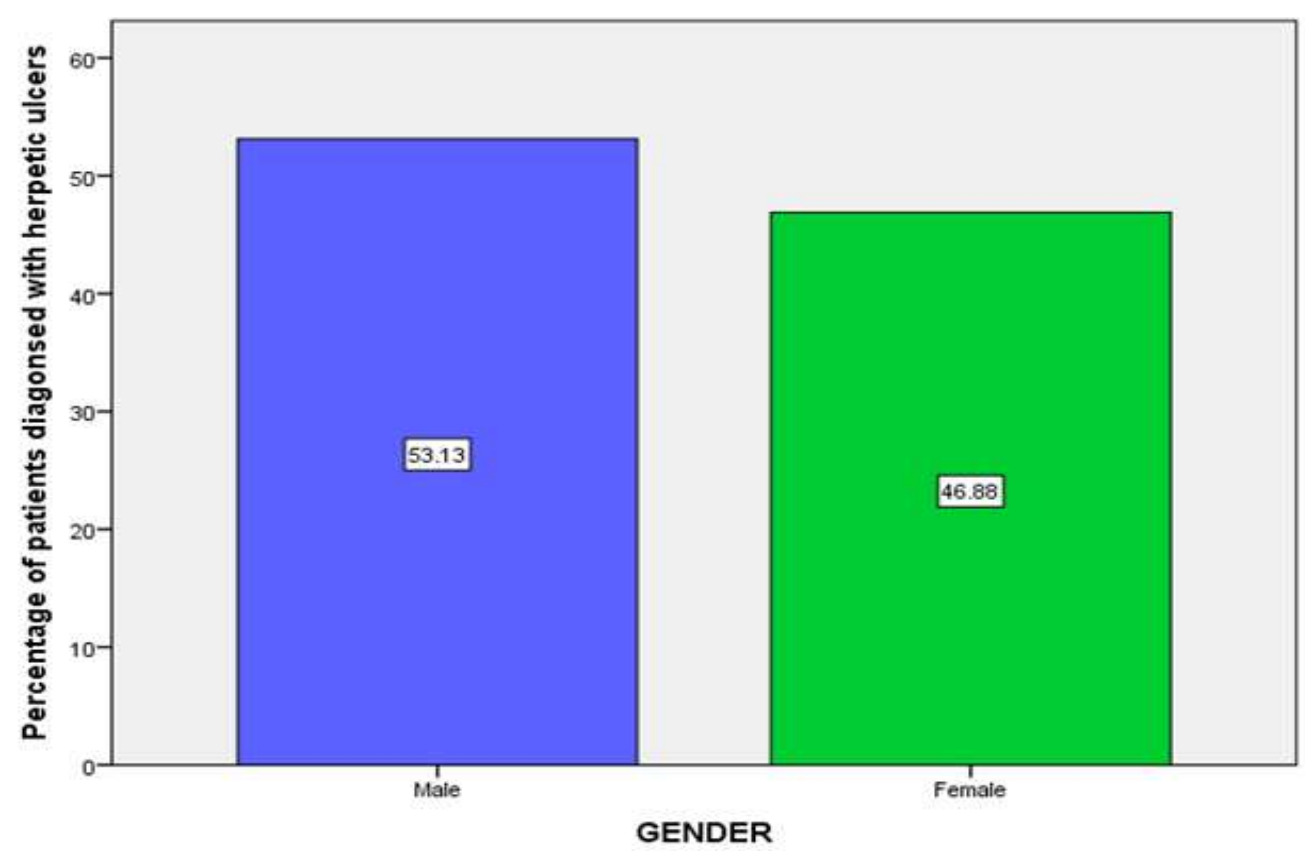

Figure 5: Bar graph depicts the percentage of males and females diagnosed with herpetic ulcers ; where $Y$ axis shows the percentage of patients diagnosed with herpetic ulcer and $X$ axis shows the gender of patients. Males (Blue) experienced a slight increase in frequency of herpetic ulcers in comparison to females (Green).

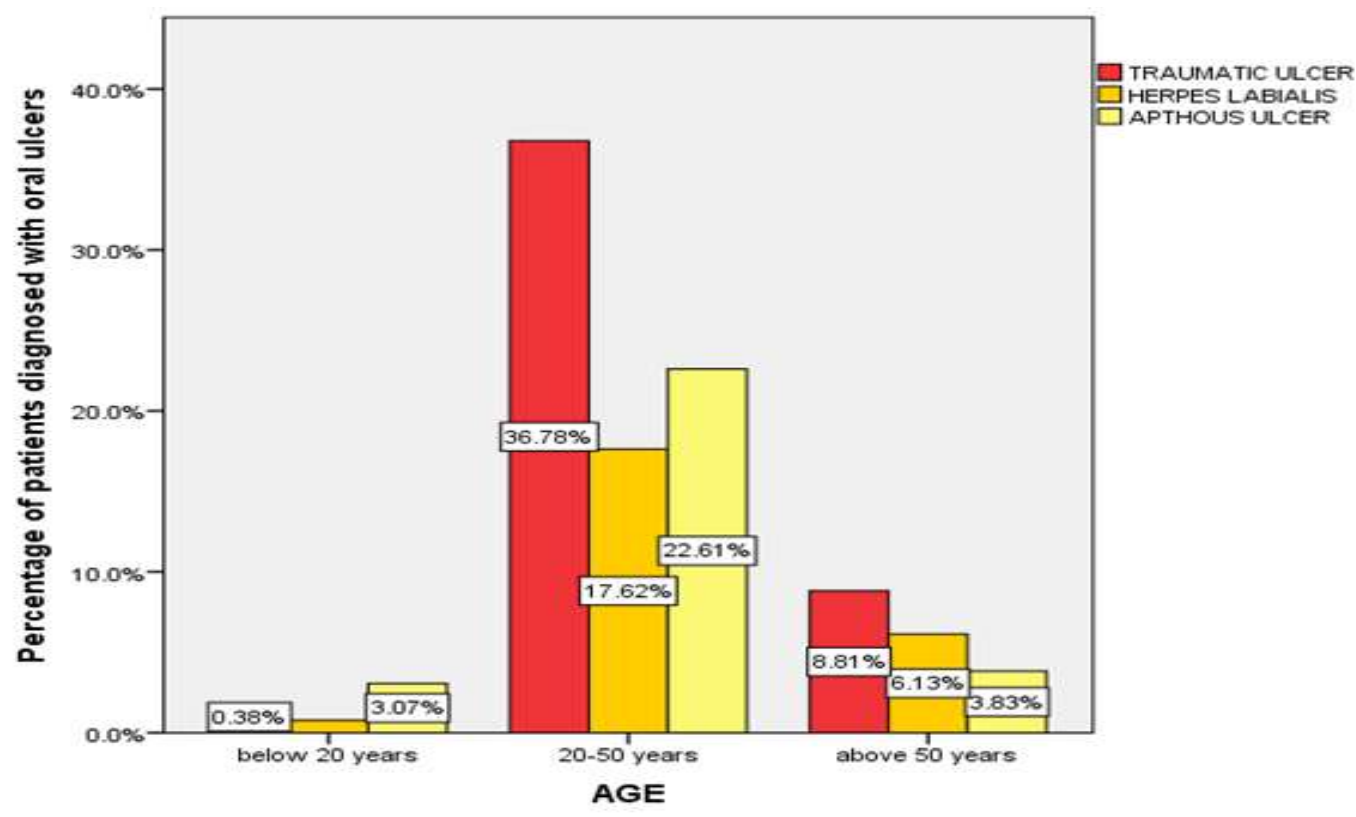

Figure 6: Bar graph depicts association between the type of ulcers and the age groups ; where $Y$ axis shows the percentage of patients diagnosed with ulcers and $X$ axis shows the various age groups. Chi square test was done and association was found to be statistically significant ; Pearson's value:10.086, DF:4, p value: $0.039(<0.05)$ hence statistically significant, proving there is an association between age groups and types of ulcers. Various types of ulcers are predominantly observed in the age group between 20-50 years among which traumatic ulcers (Red) have higher prevalence in comparison to herpetic ulcers (Orange) and aphthous ulcers (Yellow). 


\section{CONCLUSION}

With the limitations of our current study, it is concluded that the prevalence of oral ulcers was $0.59 \%$ in the patients reporting to an institution set up in Chennai, among which traumatic ulcers accounted for more than $50 \%$ of the ulcers. There was a decreased prevalence of oral ulcers among the study population indicating that the population of Chennai did not seek professional help for the treatment of oral ulcers, which implicates that knowledge and awareness of oral ulcers was less among the study population and more awareness need to be brought about by medical camps amongst the population in order to alleviate the pain of the patients suffering from oral ulcer.

\section{AUTHOR CONTRIBUTIONS}

Jembulingam performed the analysis, interpretation and wrote the manuscript. Dr Manjari contributed to conception, data design, analysis, interpretation and critically revised the manuscript. Dr Madhulaxmi helped in coordinating the research and was one of the reviewers. All the authors have discussed the results and contributed to the final manuscript.

\section{ACKNOWLEDGEMENT}

The authors are thankful to the institution and its information technology department for providing access to the database needed for the sample collection towards the completion of the study.

\section{CONFLICTS OF INTEREST}

The authors declare no conflicts of interest.

\section{REFERENCES}

[1] Abdullah MJ. Prevalence of recurrent aphthous ulceration experience in patients attending Piramird dental speciality in Sulaimani City [Internet]. Journal of Clinical and Experimental Dentistry. 2013. p. e89-94. Available from: http://dx.doi.org/10.4317/jced.51042

[2] Subashri A, Uma Maheshwari TN. Knowledge and attitude of oral hygiene practice among dental students [Internet]. Vol. 9, Research Journal of Pharmacy and Technology. 2016. p. 1840. Available from: http://dx.doi.org/10.5958/0974360x.2016.00375.9

[3] Muthukrishnan A, Kumar LB. Actinic cheilosis: early intervention prevents malignant transformation [Internet]. BMJ Case Reports. 2017. p. bcr2016218654. Available from: http://dx.doi.org/10.1136/bcr-2016-218654

[4] Venugopal A, Maheswari TNU. Expression of matrix metalloproteinase- 9 in oral potentially malignant disorders: A systematic review [Internet]. Vol. 20, Journal of Oral and Maxillofacial Pathology. 2016. p. 474. Available from: http://dx.doi.org/10.4103/0973029x.190951 
[5] Maheswari TNU, Venugopal A, Sureshbabu N, Ramani P. Salivary micro RNA as a potential biomarker in oral potentially malignant disorders: A systematic review [Internet]. Vol. 30, Tzu Chi Medical Journal. 2018. p. 55. Available from: http://dx.doi.org/10.4103/tcmj.tcmj_114_17

[6] Misra S, Shankar Y, Rastogi V, Maragathavalli G. Metastatic hepatocellular carcinoma in the maxilla and mandible, an extremely rare presentation [Internet]. Vol.

6, Contemporary Clinical Dentistry. 2015. p. 117. Available from: http://dx.doi.org/10.4103/0976237x.152966

[7] Muthukrishnan A, Warnakulasuriya S. Oral health consequences of smokeless tobacco use. Indian J Med Res. 2018 Jul;148(1):3540.

[8] Leão JC, Gomes VB, Porter S. Ulcerative lesions of the mouth: an update for the general medical practitioner. Clinics . 2007 Dec;62(6):769-80.

[9] Patil SR, Maragathavalli G, Araki K, AlZoubi IA, Sghaireen MG, Gudipaneni RK, et al. Three-Rooted Mandibular First Molars in a Saudi Arabian Population: A CBCT Study [Internet]. Vol. 18, Pesquisa Brasileira em Odontopediatria e Clínica Integrada. 2018. p. e4133. Available from: http://dx.doi.org/10.4034/pboci.2018.181.87

[10] Mortazavi H, Safi Y, Baharvand M,

Rahmani S. Diagnostic Features of Common Oral Ulcerative Lesions: An
Updated Decision Tree [Internet]. Vol. 2016, International Journal of Dentistry. 2016. p. 1-14. Available from: http://dx.doi.org/10.1155/2016/7278925

[11] Bruce AJ, Rogers RS. Acute oral ulcers [Internet]. Vol. 21, Dermatologic Clinics. 2003. p. 1-15. Available from: http://dx.doi.org/10.1016/s07338635(02)00064-5

[12] Azodo CC, Umoh AO. Herpes labialis among dental healthcare providers in Nigeria [Internet]. Vol. 6, Indian Journal of Dentistry. 2015. p. 116. Available from: http://dx.doi.org/10.4103/0975962x.158186

[13] Chaitanya N, Muthukrishnan A, Krishnaprasad CMS, Sanjuprasanna G, Pillay P, Mounika B. An insight and update on the analgesic properties of vitamin $\mathrm{C}$ [Internet]. Vol. 10, Journal of Pharmacy And Bioallied Sciences. 2018. p. 119. Available from: http://dx.doi.org/10.4103/jpbs.jpbs_12_18

[14] Jasper J, Roithmann S, Camilotti RS, Salum FG, Cherubini K, de Figueiredo MAZ. Effect of G-CSF on oral mucositis and traumatic ulcers produced in the tongue of rats undergoing radiotherapy: clinical and histologic evaluation [Internet]. Vol. 122, Oral Surgery, Oral Medicine, Oral Pathology and Oral Radiology. 2016. p. 587-96. Available from: http://dx.doi.org/10.1016/j.oooo.2016.07.02 1 
[15] Chaitanya NC, Muthukrishnan A, Babu DBG, Kumari CS, Lakshmi MA, Palat G, et al. Role of Vitamin $\mathrm{E}$ and Vitamin $\mathrm{A}$ in Oral Mucositis Induced by Cancer Chemo/Radiotherapy- A Meta-analysis. J Clin Diagn Res. 2017 May;11(5):ZE06-9.

[16] Muthukrishnan A, Kumar LB, Ramalingam G. Medication-related osteonecrosis of the jaw: a dentist's nightmare [Internet]. BMJ Case Reports. 2016. p. bcr2016214626. Available from: http://dx.doi.org/10.1136/bcr-2016-214626

[17] Choudhury P. Vanishing Roots: First Case Report of Idiopathic Multiple CervicoApical External Root Resorption [Internet]. JOURNAL OF CLINICAL AND DIAGNOSTIC RESEARCH. 2015. Available from: http://dx.doi.org/10.7860/jcdr/2015/11698.5 668

[18] Altenburg A, El-Haj N, Micheli C, Puttkammer M, Abdel-Naser M, Zouboulis CC. The Treatment of Chronic Recurrent Oral Aphthous Ulcers [Internet]. Deutsches Aerzteblatt Online. 2014. Available from: http://dx.doi.org/10.3238/arztebl.2014.0665

[19] Elfering L, van der Sluis WB, Mermans JF, Buncamper ME. Herpes neolabialis: herpes simplex virus type 1 infection of the neolabia in a transgender woman. Int J STD AIDS. 2017 Jul;28(8):841-3.

[20] Karthikeyan P, Aswath N. Stress as an etiologic co-factor in recurrent aphthous ulcers and oral lichen planus [Internet]. Vol.
58, Journal of Oral Science. 2016. p. $237-$ 40. Available from: http://dx.doi.org/10.2334/josnusd.15-0610

[21] Dharman S, Muthukrishnan A. Oral mucous membrane pemphigoid - Two case reports with varied clinical presentation [Internet]. Vol. 20, Journal of Indian Society of Periodontology. 2016. p. 630. Available from:

http://dx.doi.org/10.4103/jisp.jisp_155_16

[22] Kurklu-Gurleyen E, Ogut-Erisen M, Cakir O, Uysal O, Ak G. Quality of life in patients with recurrent aphthous stomatitis treated with a mucoadhesive patch containing citrus essential oil [Internet]. Patient Preference and Adherence. 2016. p. 967. Available from: http://dx.doi.org/10.2147/ppa.s106530

[23] Rohini S, Jayanth Kumar V. Incidence of dental caries and pericoronitis associated with impacted mandibular third molar-A radiographic study [Internet]. Vol. 10, Research Journal of Pharmacy and Technology. 2017. p. 1081. Available from: http://dx.doi.org/10.5958/0974360x.2017.00196.2

[24] Subha M, Arvind M. Role of Magnetic Resonance Imaging in Evaluation of Trigeminal Neuralgia with its Anatomical Correlation [Internet]. Vol. 12, Biomedical and Pharmacology Journal. 2019. p. 28996. Available from: http://dx.doi.org/10.13005/bpj/1640 [25] Steele JC, Clark HJ, Hong CHL, Jurge S, 
Muthukrishnan A, Kerr AR, et al. World Workshop on Oral Medicine VI: an international validation study of clinical competencies for advanced training in oral medicine. Oral Surg Oral Med Oral Pathol Oral Radiol. 2015 Aug;120(2):143-51.e7.

[26] Shulman JD, Beach MM, Rivera-Hidalgo F. The prevalence of oral mucosal lesions in U.S. adults: data from the Third National Health and Nutrition Examination Survey, 1988-1994. J Am Dent Assoc. 2004 Sep;135(9):1279-86.

[27] Westert GP, Schellevis FG, de Bakker DH, Groenewegen PP, Bensing JM, van der Zee J. Monitoring health inequalities through general practice: the Second Dutch National Survey of General Practice [Internet]. Vol. 15, European Journal of Public Health. 2005. p. 59-65. Available from: http://dx.doi.org/10.1093/eurpub/cki116

[28] Cebeci, Ali-Riza-Ilker \& Gulsahi, Ayse \& Kamburoğlu, Kivanç \& Orhan, BüyükKaan \& Oztaş, Bengi. Prevalence and distribution of oral mucosal lesions in an adult Turkish population. Medicina oral, patología oral y cirugía bucal. 2009;14:E272-7.

[29] Chaudhuri S, Dey S, Bajpai RC. Prevalence of oral ulcers and its association with addictions in rural population of western Uttar Pradesh and eastern Rajasthan [Internet]. Vol. 6, Journal of Oral Biology and Craniofacial Research. 2016. p. 17986.

Available

from: http://dx.doi.org/10.1016/j.jobcr.2016.04.00 3

[30] Oyetola EO, Mogaji IK, Agho TO, Ayilara OA. PATTERN OF PRESENTATION OF ORAL ULCERATIONS IN PATIENTS ATTENDING AN ORAL MEDICINE CLINIC IN NIGERIA. Ann Ib Postgrad Med. 2018 Jun;16(1):9-11.

[31] Amadori F, Bardellini E, Conti G, Majorana A. Oral mucosal lesions in teenagers: a cross-sectional study [Internet]. Vol. 43, Italian Journal of Pediatrics. 2017. Available from: http://dx.doi.org/10.1186/s13052-017-03677

[32] Zain RB. Oral recurrent aphthous ulcers/stomatitis. Prevalence in Malaysia and an epidemiological update [Internet]. Vol. 42, Journal of Oral Science. 2000. p. 15-9. Available from: http://dx.doi.org/10.2334/josnusd.42.15

[33] Ashwinirani SR, Rajmane Y, Suragimath G, Nayak A, Rajmane V, Lohana M. Prevalence of recurrent aphthous stomatitis in western population of Maharashtra, India [Internet]. Vol. 9, Journal of Oral Research and Review. 2017. p. 25. Available from: http://dx.doi.org/10.4103/jorr.jorr_33_16 